ARTICLE

\title{
Background Dose for Systemic Targeted Alpha Therapy
}

\author{
Chen-Yu HUANG ${ }^{1,2}$ Susanna GUATELLI ${ }^{3}$ \\ Bradley M. OBORN ${ }^{3,4}$ and Barry J. ALLEN ${ }^{1,2 *}$ \\ ${ }^{1}$ St. George Clinical School, University of New South Wales, Kogarah, NSW 2217Australia \\ ${ }^{2}$ Centre for Experimental Radiation Oncology (CERO), St George Hospital, Kogarah, NSW 2217 Australia \\ ${ }^{3}$ Centre for Medical Radiation Physics, University of Wollongong, Wollongong, NSW 2522 Australia \\ ${ }^{4}$ Illawarra Cancer Care Centre, Wollongong Hospital, Wollongong, NSW 2500 Australia
}

\begin{abstract}
The phase 1 clinical trial of systemic Targeted Alpha Therapy for metastatic melanoma has shown that solid tumours can be regressed by alpha radiation. However, patient blood vessels and lymphocytes inevitably received a background radiation from non-targeted alpha decays in the blood circulation. To determine the toxicity of alpha particle to normal tissue capillaries and peripheral blood lymphocytes, capillary and lymphocyte models were established with Geant4 Monte Carlo microdosimetry technique. The specific energy deposited in a capillary endothelial cell nucleus or lymphocyte nucleus per radioactive decay and the cell survival rates were calculated for the source constrained in the vessel. The specific energy to lymphocytes depends on the type of blood vessels, with survival rates between $89 \%$ and $98 \%$. The relationship between calculated specific energy and micronuclei data obtained in a clinical trial was determined, further establishing this technique as a biological dosimeter for Targeted Alpha Therapy. The 2 cGy dose to the capillary endothelial cell nucleus was found to be negligible. These results show that systemic Targeted Alpha Therapy is safe for the function of lymphocytes and normal tissue capillaries.
\end{abstract}

KEYWORDS: Targeted Alpha Therapy, microdosimetry, Monte Carlo, Geant4, endothelial cell, lymphocyte

\section{Introduction}

Melanoma lesions experienced marked regression after systemic Targeted Alpha Therapy (TAT) in several patients of a phase 1 clinical trial. ${ }^{1)}$ In this study, the melanoma specific monoclonal antibody 9.2.27 was chelated to alpha emitter ${ }^{213} \mathrm{Bi}$. This alpha-immunoconjugate ${ }^{213} \mathrm{Bi}$ - cDTPA9.2.27 (AIC) was systematically administrated into patients to kill isolated cells and cell clusters, and so stop the development of lethal metastatic cancer. While adverse events were not observed, the radioisotope will circulate with blood and post a background dose to the vascular system. This is a potential hazard and might be a stochastic cause of secondary cancer.

Lymphocytes (LCs) in the blood and endothelial cells (ECs) of normal capillaries are two potential victims of this background dose and were chosen to evaluate the non-specific background damage of the alpha irradiation. Alpha particles have a high linear energy transfer (LET) and can deposit a highly variable dose to these cells. Thus a microdosimetry technique is essential to investigate the physical properties of TAT.

The Geant4 Monte Carlo code was adopted to build up LC and capillary EC models. Because 9.2.27 is not a specific antibody for healthy LC and ECs, the non-targeted source was assumed to be uniformly distributed in the blood. The single-hit specific energy distribution of radioisotope source ${ }^{213} \mathrm{Bi}$ was calculated for each model and the specific energy

*Corresponding author, E-mail: bjallen@unsw.edu.au

(c) 2011 Atomic Energy Society of Japan, All Rights Reserved. for LCs was determined in different size vessels.

Direct exposure to ionizing radiation induces an increase in the frequency of apoptosis and micronucleus (MN) formation. The cytokinesis-block micronucleus assay allows these $\mathrm{MN}$ to be counted, providing an in situ biological dosimeter. ${ }^{2)}$ In this study, we evaluated the MN frequency in peripheral blood LCs after in vitro incubation with the AIC. A conversion function between specific energy for LC and the number of $\mathrm{MN}$ was developed. Further, the simulation results were applied to quantitatively analyse patient safety in the phase 1 clinical trial of systemic TAT for melanoma.

\section{Method}

\section{Geant4 Monte Carlo Simulation}

Geant4 is a Monte Carlo Toolkit for the simulation of the passage of particles through matter. ${ }^{3)}$ In this study Geant4 version 9.3 was adopted to identify the critical physical features of radiation in the LC and EC nucleus. The Geant4 Low Energy Physics was selected to model the particle interaction with the water materials involved in the experiment. The threshold of production for secondary particles was $250 \mathrm{eV}$.

A useful source of alphas is ${ }^{213} \mathrm{Bi}$ with half-life of 45.6 minutes and was chosen in the clinical trial. ${ }^{1)}$ In this study, beta and gamma decay products from ${ }^{213} \mathrm{Bi}$ were ignored as their contribution to the dose is negligible. ${ }^{4)}$ Only alpha particles, with intensities of $98 \%$ at $8.4 \mathrm{MeV}$ and $2 \%$ at 5.8 $\mathrm{MeV}$, were included.

The energy deposition $\varepsilon$ is a fundamental parameter in microdosimetry arising from a single traversal of the target 
volume. The energy deposition of an alpha particle and its secondary particles in the LC and EC nucleus were recorded and processed.

The coordinates of intersection between the alpha particle track and the cell nucleus were recorded. $\mathrm{P}_{\mathrm{a}}$ is entry coordinate and $\mathrm{P}_{\mathrm{b}}$ the exit coordinate. Here we assume alpha particle track is straight. The chord length $l$ of a traversal is:

$$
\begin{aligned}
& l=\mathrm{P}_{\mathrm{b}}-\mathrm{P}_{\mathrm{a}} \quad \mu \mathrm{m} \\
& \text { The LET is given by: } \\
& \text { LET }=\varepsilon / l \quad \mathrm{keV} / \mu \mathrm{m}
\end{aligned}
$$

The specific energy $\mathrm{z}$ is the energy deposition (Joule) per unit mass $(\mathrm{kg})$ of the target:

$$
\mathrm{z}=\varepsilon / \mathrm{m} \quad \text { Gy }
$$

The event distribution was calculated for deposited energy, LET and specific energy. The weighted average values were calculated from the event distributions.

\section{Lymphocyte Model}

The LC and its nucleus can be modeled as two eccentric ellipsoids. The morphometric scheme of a LC is presented in Fig. 1. ${ }^{5)}$ The long axis are $7.33 \mu \mathrm{m}$ for the cell and $6.2 \mu \mathrm{m}$ for its nucleus. The ratio of major and minor axes of LCs and nucleus is 1.1 and 1.2 respectively. The displacement of the nucleus is assumed to be $0.3 \mu \mathrm{m}$ and the mean value for off-orientation is about $10^{\circ}$. The nuclear density is assumed to be $1.0 \mathrm{~g} / \mathrm{cm}^{3}$. LC cytoplasm and surrounding blood material were assumed as liquid water.

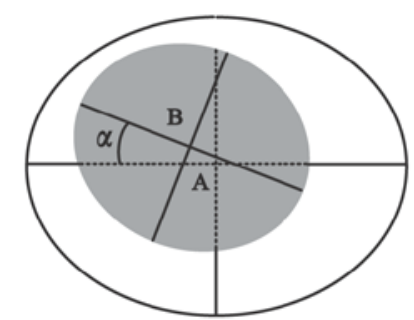

Fig. 1 Morphometric scheme of Lymphocyte Model

The LC was positioned in vessels with $50 \mu \mathrm{m}$ length and various diameters.

\section{Capillary Endothelial Cell Model}

The normal tissue capillary EC geometry was constructed by building up a $50 \mu \mathrm{m}$ long, $8 \mu \mathrm{m}$ inner and $10 \mu \mathrm{m}$ outer diameter tube ${ }^{6)}$ with an oval nucleus on the internal wall (Fig. 2). The EC nucleus was an ellipsoid with radius axes of $5 \times 2.35 \times 1.85 \mu \mathrm{m}$ (the radius taken from transmission electron micrographs ${ }^{7)}$ of endothelial nuclei measurement) and with a density of $1.0 \mathrm{~g} / \mathrm{cm}^{3}$. The nucleus was oriented parallel to the axis of the blood vessel. EC cytoplasm, blood and peripheral cells material were assumed as liquid water.

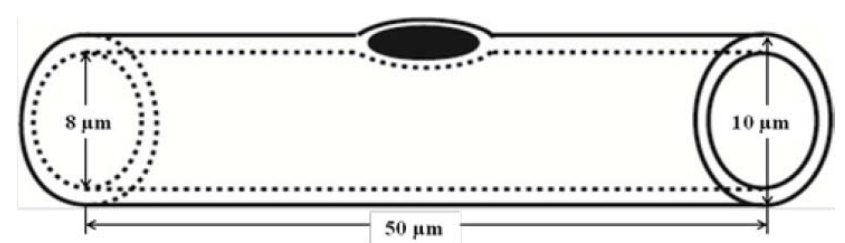

Fig. 2 Capillary geometry of hollow cylinder with an ellipsoidal cell nucleus in the wall
Activity in the blood would give the vasculature system a background radiation dose. To determine whether the background dose would damage the capillary ECs, alpha particles were randomly emitted from within the capillary lumen.

\section{Result}

\section{Lymphocyte and Capillary EC Models}

The average deposited energy of an alpha particle when it traverses the LC and EC nuclei was 274 and $226 \mathrm{keV}$; the mean LET was 73 and $66 \mathrm{keV} / \mu \mathrm{m}$ respectively. The specific energy per traversal over the nucleus target volume was 0.5 Gy for the LC model and 0.4 Gy for the capillary EC model. The energy deposition $\varepsilon$ was higher for the LC because the size of its nucleus was larger allowing more deposited energy. The probability of traversal in LC model was calculated in a capillary source setting. The results for TAT microdosimetry for the LC and capillary EC models are given in Table 1.

Table 1 Average Parameters in TAT microdosimetry

\begin{tabular}{cccccc}
\hline Model & $\begin{array}{c}\varepsilon \text { per } \\
\text { traversal } \\
(\mathrm{keV})\end{array}$ & $\begin{array}{c}\text { LET } \\
(\mathrm{keV} / \mu \mathrm{m})\end{array}$ & $\begin{array}{c}\text { z per } \\
\text { traversal } \\
(\mathrm{Gy})\end{array}$ & $\begin{array}{c}\text { Probability } \\
\text { of traversal } \\
(\%)\end{array}$ & $\begin{array}{c}\text { Mean z } \\
\text { per } \\
\text { decay } \\
(\mathrm{cGy})\end{array}$ \\
\hline $\begin{array}{c}\text { Lymphocyte } \\
\text { Capillary }\end{array}$ & 274 & 73 & 0.5 & 2.7 & 1.4 \\
\hline
\end{tabular}

The probability distribution for the specific energy within the target volume from single traversal is referred to as the single-hit specific energy distribution spectrum, as shown in Fig. 3.

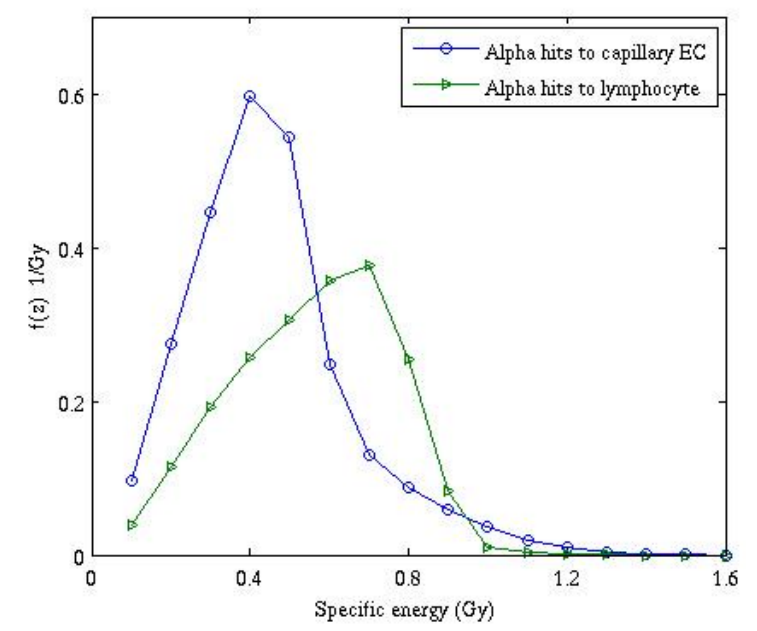

Fig. 3 Normalized single-hit specific energy distribution in the LC and capillary EC model

When ${ }^{213} \mathrm{Bi}$ atoms are near the boundary of a vessel, about half of the emitted alpha particles escape the blood vessel. This boundary effect has to be taken into account. In this case a LC was placed at the center of a $50 \mu \mathrm{m}$ long vessel with the following diameters: arteriole $(30 \mu \mathrm{m})$, capillary $(8$ $\mu \mathrm{m})$ and venules $\left.(20 \mu \mathrm{m}) .{ }^{6}\right)$ When the vessel radius exceed the $80 \mu \mathrm{m}$ range of alpha particles, the boundary effect abates because the particles emitted near vessel wall won't have opportunity to reach the LC nucleus. 
The administered AIC in the melanoma clinical trial contained up to $25 \mathrm{mCi}$ of ${ }^{213} \mathrm{Bi}^{8)}$ The total number of ${ }^{213} \mathrm{Bi}$ atom $\left(\mathrm{t}_{1 / 2}=45.6 \mathrm{~min}=2736 \mathrm{sec}\right)$ present in the $25 \mathrm{mCi}$ $\left(9.25 \times 10^{8} \mathrm{~Bq}\right)$ was

$\mathrm{N}_{\text {total-atom }}=\mathrm{A} / \lambda=9.25 \times 10^{8} /(0.693 / 2736)=3.65 \times 10^{12}$

in which $\lambda$ is a decay constant calculated by $0.693 /$ isotope half life.

The ${ }^{213} \mathrm{Bi}$ concentration $\left(\mathrm{C}_{\mathrm{Bi}}\right)$ was constatnt in each vessel so the total number of disintegration of above three vessels was different. Assume there is 5 liters of blood in the body, ${ }^{9}$ then:

$\mathrm{C}_{\mathrm{Bi}}=3.65 \times 10^{12} / 5 \mathrm{~L}=7.3 \times 10^{-4}$ atom $/ \mu \mathrm{m}^{3}$

The vessel diameter determines the number of traversals (Table 2). The background dose for one central LC nucleus was 2.5 cGy in capillary, $9.6 \mathrm{cGy}$ in venule and $15.1 \mathrm{cGy}$ in arteriole (Table 2). The traversal number was the least in the capillary because the number of ${ }^{213} \mathrm{Bi}$ sources is lower.

Table 2 Number of traversal and $\mathrm{z}$ in different kind of vessels

\begin{tabular}{lll}
\hline Vessel & Traversal & $\mathrm{z}(\mathrm{cGy})$ \\
\hline arteriole & 0.29 & 15.1 \\
capillary & 0.05 & 2.5 \\
venule & 0.19 & 9.6 \\
\hline
\end{tabular}

\section{Lymphocyte Micronuclei (MN)}

Cytokinesis-blocked micronucleus assay allows the evaluation of radiation induced cytogenetic damage to LCs after ionizing radiation. ${ }^{10)}$ The AIC ${ }^{213} \mathrm{Bi}$ - cDTPA -9.2.27 was used in the clinical trial. 9.2.27 is an $\operatorname{IgG} 2$ a mouse monoclonal antibody, reactive with the melanoma MCSP antigen, which is not expressed on LCs. As such, there is no significant targeting effect with the AIC. Blood from three healthy human volunteers was collected and LCs were isolated and irradiated in vitro with activities of 10-1200 $\mathrm{kBq}$ of ${ }^{213} \mathrm{Bi}$ - cDTPA -9.2.27. ${ }^{11)}$ The MN frequency was determined by the analysis of 1000 binucleated cells per subject. The total activity and number of MNs formed is shown in Table 3.

Table 3 Average MN, total z vs activity

\begin{tabular}{lll}
\hline $\begin{array}{l}\text { Activity } \\
\text { of }{ }^{213} \mathrm{Bi} \\
(\mathrm{kBq} / \mathrm{mL})\end{array}$ & $\begin{array}{l}\text { Average } \\
\mathrm{MN}^{12)}\end{array}$ & $\begin{array}{l}\text { Total } \\
\mathrm{z}(\mathrm{Gy})\end{array}$ \\
\hline 0 & 20 & 0 \\
15 & 38 & 0.1 \\
30 & 70 & 0.2 \\
60 & 69 & 0.4 \\
90 & 164 & 0.6 \\
120 & 210 & 0.8 \\
150 & 220 & 1.0 \\
300 & 391 & 1.9 \\
600 & 676 & 3.8 \\
\hline
\end{tabular}

The specific energy to one LC nucleus was derived by Geant 4 simulation calculation in the third column.

A quadratic relationship between specific energy and number of MN was observed and is shown in Fig 4. The fitted equation is established as formula 6 .

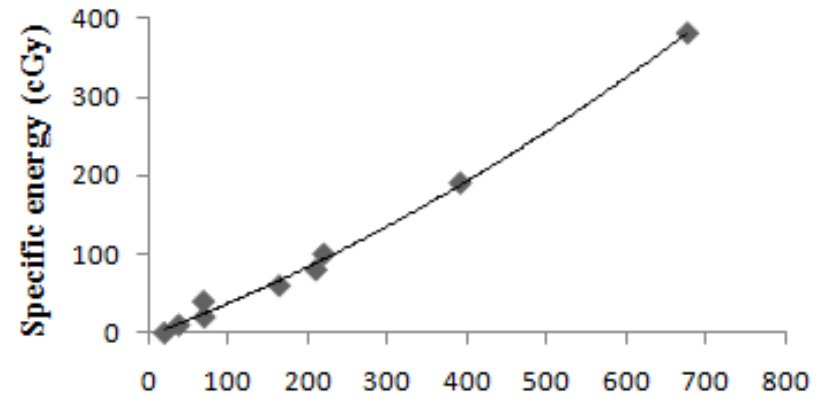

Number of MN

Fig. $4 \quad \mathrm{z}$ and $\mathrm{MN}$ response relationship

$$
\mathrm{z}=0.0003 \mathrm{MN}^{2}+0.4 \mathrm{MN}-3.4
$$

This function built up a bridge between injected activity, specific energy and biological endpoints. It can be used to predict the biological effective dose by counting number of $\mathrm{MN}$ in 1000 binucleated cells under the light microscope.

\section{Dose to Capillary EC Nucleus}

In the clinical trial case, the number of ${ }^{213} \mathrm{Bi}$ atoms in the volume of one capillary lumen volume of $2.5 \times 10^{-12}$ liter $\left(\pi \mathrm{r}^{2} \cdot \mathrm{L}\right)$ was:

$\mathrm{N}_{\text {Bi-in-lumen }}=\mathrm{N}_{\text {total-atom }} \times$ volume ratio $=3.65 \times 10^{12} \times$ $\left(2.5 \times 10^{-12} / 5\right)=1.8$

The actual background dose to the EC nucleus was calculated by multiplying the specific energy of single ${ }^{213} \mathrm{Bi}$ decay and the number of ${ }^{213} \mathrm{Bi}$ atoms in the lumen:

Dose $_{\text {per-EC-nucleus }}=$ Dose $_{\text {per-traversal }} \times \mathrm{N}_{\text {Bi-in-lumen }}$

$=1.1 \mathrm{cGy} \times 1.8=2 \mathrm{cGy}$

The background dose for one normal tissue capillary nucleus was $2 \mathrm{cGy}$. The small number of decays gave a large standard deviation of $1.4 \mathrm{cGy}$.

\section{Cell Survival Fraction}

The specific energy data can be used to estimate the fraction of cell survivors by a biological cell inactivation model. ${ }^{13-15)}$ The cell surviving fraction following alpha particle irradiation is given by:

$\mathrm{S}=\mathrm{e}^{-\mathrm{D} / \mathrm{D} 0}$

where $\mathrm{D}_{0}$ is the dose to yield a $37 \%$ surviving fraction. Alpha survival experiments gave $\mathrm{D}_{0}=1.4-1.7$ Gy. ${ }^{16)}$ Note that alpha cell survival curves are relatively insensitive to the cell cycle or oxygen status.

On this basis, for $25 \mathrm{mCi}$ injected activity, the $2 \mathrm{cGy}$ background dose corresponds to about $99 \%$ survival rate for normal capillary ECs and 2.5 cGy to 15.1 cGy dose (Table 2) corresponds to $89 \% \sim 98 \%$ survival rates for LCs. A small loss of ECs and LCs is not significant.

\section{Discussion}

In the phase 1 trial of systemic Targeted Alpha Therapy for metastatic melanoma, the alpha-immunoconjugate is administrated intravenously. This systemic therapy can do harm to blood cells and endothelial cells. However, after the alpha-immunoconjugates spread throughout the whole body, the radionuclei density is small in the $5 \mathrm{~L}$ blood pool. The size of blood cells and endothelial cells is too small for the direct measurement of absorbed dose by solid state 
dosimeter. The aim of Monte Carlo microdosimetry is to calculate dose at the micrometer scale. The specific energy to the lymphocyte and endothelial cell nucleus was calculated by the Geant4 Monte Carlo simulation based on physical emission characteristics, on the properties of the medium and cell morphometry.

Cell geometry can have an important influence on the single-cell microdosimetry result. The model parameters in this study were all taken from biological measurements rather than simple physics model. The total activity in the blood was assumed to be uniform and there is no radioisotope clearance, so as to give a certain density of ${ }^{213} \mathrm{Bi}$.

A quadratic fitting function of specific energy to lymphocyte and number of micronuclei was established. Because of the simplicity of the technique and rapid assessment of the binucleated cells, we suggest the use of the micronucleus measurement of patient's blood as a biological dosimeter for systemic Targeted Alpha Therapy.

Loss of lymphocyte and endothelial cell is not significant but further study is needed to investigate how systemic Targeted Alpha Therapy affects on bone marrow stem cells.

For tumors, because of the targeting accumulation effect, the alpha-immunoconjugate dose is lethal to tumor endothelial cell (unpublished data). For endothelial cells in normal tissue, the short 45.6 minutes half life of ${ }^{213} \mathrm{Bi}$ and the low administrated radioactivity limited the absorbed dose to an acceptable point. Therefore, we conclude that the background dose to patients in Targeted Alpha Therapy is safe.

\section{References}

1) C. Raja, P. Graham, S. M. Abbas Rizvi, E. Song, H. Goldsmith, J. Thompson et al., "Interim analysis of toxicity and response in phase 1 trial of systemic targeted alpha therapy for metastatic melanoma," Cancer Biol. Ther., 6, 846-852 (2007).

2) C. Streffer, W. U. Müller, A. Kryscio, W. Böcker, "Micronuclei-biological indicator for retrospective dosimetry after exposure to ionizing radiation," Mutat. Res. Fundam. Mol. Mech. Mugag, 404, 101-105 (1998).

3) J. Allison, K. Amako, J. Apostolakis, H. Araujo, P. A. Dubois,
M. Asai et al., "Geant4 developments and applications," IEEE Trans. Nucl. Sci., 53, 270-278 (2006).

4) J. C. Roeske, T. G. Stinchcomb, "The Use of Microdosimetric Moments in Evaluating Cell Survival for Therapeutic Alpha-Particle Emitters," Radiat. Res., 151, 31-38 (1999).

5) V. A. Loiko, G. I. Ruban, O. A. Gritsai, A. D. Gruzdev, S. M. Kosmacheva, N. V. Goncharova et al., "Morphometric model of lymphocyte as applied to scanning flow cytometry," J. Quant. Spectr. Rad. Transfer, 102, 73-84 (2006).

6) R. M. Berne, M. N. Levy, Cardiovascular Physiology, Mosby, St Louis, (1986).

7) S. Deguchi, K. Maeda, T. Ohashi, M. Sato. "Flow-induced hardening of endothelial nucleus as an intracellular stress-bearing organelle," J. Biomech., 38, 1751-1759 (2005).

8) B. J. Allen, "Clinical trials of targeted alpha therapy for cancer," Rev. Recent Clin. Trials, 3, 185-191 (2008).

9) C. Starr, R. Taggart, Biology: The Unity and Diversity of Life, Wadsworth Publishing Company (1995).

10) Vijayalaxmi, B. Z. Leal, T. S. Deahl, M. L. Meltz, "Variability in adaptive response to low dose radiation in human blood lymphocytes: consistent results from chromosome aberrations and micronuclei," Mutat. Res., 348, 45-50 (1995).

11) E. Y. Song, S. M. Rizvi, C. F. Qu, C. Raja, J. Yuen, Y. Li et al., "The cytokinesis-block micronucleus assay as a biological dosimeter for targeted alpha therapy," Phys. Med. Biol., 53, 319-28 (2008).

12) E. Y. Song, Targeted Alpha Therapy for Ovarian and Other Cancers, University of New South Wales (2006).

13) J. L. Humm, L. M. Chin. "A model of cell inactivation by alpha-particle internal emitters," Radiat. Res., 134, 143-150 (1993).

14) T. G. Stinchcomb, J. C. Roeske, "Analytic microdosimetry for radioimmunotherapeutic alpha emitters," Med. Phys., 19, 1385-1393 (1992).

15) D. E. Charlton, R. Sephton, "A Relationship between Microdosimetric Spectra and Cell Survival for High-LET Irradiation," Int. J. Radiat. Biol., 59, 447-457 (1991).

16) S. J. Kennel, M. Stabin, J. C. Roeske, L. J. Foote, P. K. Lankford, M. Terzaghi-Howe et al., "Radiotoxicity of Bismuth-213 Bound to Membranes of Monolayer and Spheroid Cultures of Tumor Cells," Radiat. Res., 151, 244-256 (1999). 